ENVIRONMENTAL RESTORATION PROGRAM

\section{A Preliminary Study of the Controls on Melting During In Situ Vitrification}

\author{
A. D. Solomon \\ J. E. Nyquist \\ V. Alexiades \\ G. K. Jacobs \\ S. M. Lenhart
}


This report has been reproduced directly from the best available copy.

Available to DOE and DOE contractors from the Office of Scientific and Technical Information, P.O. Box 62, Oak Rióge, TN 37831; prices avallable from 615-576-8401, FTS 626-8401.

Available to the public from the National Technical Information Service, U.S. Department of Commerce, 5285 Port Royal Rd., Springfield, VA 22161. 
Environmental Restoration Division

ORNL Environmental Restoration Program

\title{
A Preliminary Study of the Controls on Melting During In Situ Vitrification
}

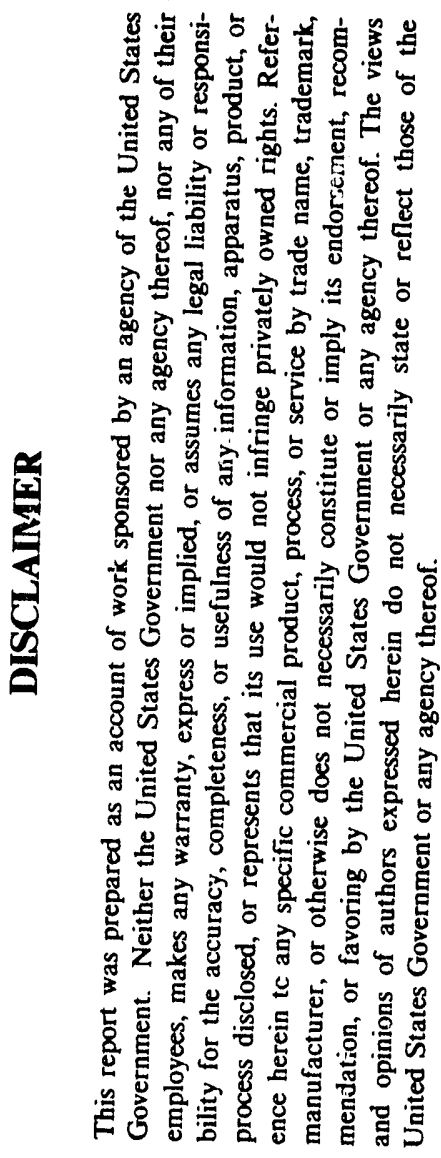
A. D. Solomon
J. E. Nyquist
V. Alexiades
G. K. Jacobs
S. M. Lenhart

Manuscript Completed-January 1991

Date Issued-Deccmber 1991

\author{
Prepared by \\ Environmental Sciences Division \\ Oak Ridge National Laboratory \\ ESD Publication 3608 \\ Prepared for \\ U.S. Department of Energy
}

Office of Environmental Restoration and Waste Management under budget and reporting code EW 20

OAK RIDGE NATIONAL LABORATORY

Oak Ridge, Tennessee 37831-6285

managed by

MARTIN MARIETTA ENERGY SYSTEMS, INC.

for the

U.S. DEPARTMENT OF ENERGY

under contract DE-AC05-84OR21400 


\section{Author Affiliations}

Alan D. Solomon is a consultant from Omer, Israel. Jon E. Nyquist and Gary $\mathrm{K}$. Jacobs are members of the Environmental Sciences Division of Oak Ridge National Laboratory, Martin Marietta Energy Systems, Inc. Vasilios Alexiades and Suzanne $M$. Lenhart are members of the Engineering Physics and Mathematics Division, Oak Ridge National Laboratory, and The University of Tennessee. 


\section{CONTENTS}

ACKNOWLEDGMENTS $\ldots \ldots \ldots \ldots \ldots \ldots \ldots \ldots \ldots \ldots \ldots \ldots \ldots$

MATHEMATICAL SYMBOLS $\ldots \ldots \ldots \ldots \ldots \ldots \ldots \ldots \ldots \ldots \ldots, \ldots \ldots$ vii

EXECUTIVE SUMMARY $\ldots \ldots \ldots \ldots \ldots \ldots \ldots \ldots \ldots \ldots \ldots \ldots \ldots \ldots$ ix

1. INTRODUCTION $\ldots \ldots \ldots \ldots \ldots \ldots \ldots \ldots \ldots \ldots \ldots \ldots \ldots \ldots \ldots \ldots \ldots \ldots$

2. DEVELOPMENT OF AL'TERNATIVE

CONCEPTUAL MODELS ......................... 5

2.1 HEAT TRANSFER MECHANISMS IN ISV ............... 5

2.2 HEAT BALANCE AND DEPTH BASED ON DATA $\ldots \ldots \ldots \ldots \ldots \ldots$

2.3 A MODEL CONSISTENT WITH DATA $\ldots \ldots \ldots \ldots \ldots \ldots \ldots \ldots, 6$

3. DEVELOPMENT NEEDS FOR ISV MODELS $\ldots \ldots \ldots \ldots \ldots \ldots \ldots, 9$

4. DERIVATION OF DEPTH VS TIME RELATIONSHIPS ........... 11 4.1 SQUARE-ROOT-OF-TIME DEPENDENCE OF

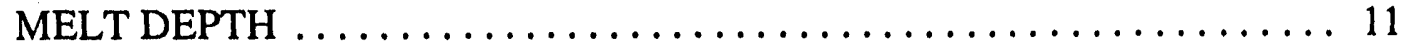

4.2 MODEL OF MELT PROGRESSION AS A

FUNCTION OF TIME $\ldots \ldots \ldots \ldots \ldots \ldots \ldots \ldots \ldots \ldots \ldots \ldots, 12$

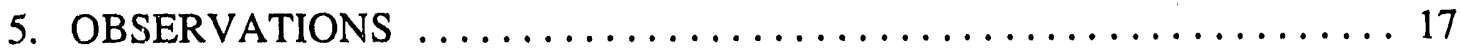

5.1 NOTES ON THE PNL EXPERIMENTS $\ldots \ldots \ldots \ldots \ldots \ldots \ldots \ldots \ldots, 17$

5.2 NOTES ON THE ORNL EXPERIMENT $\ldots \ldots \ldots \ldots \ldots \ldots \ldots \ldots 24$

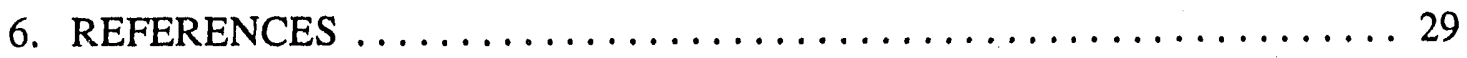




\section{ACKNOWLEDGMENTS}

The authors wish to thank Sid Garland for providing funding through the Environmental Restoration Division for this preliminary study. We are grateful to Brian Spalding and John Drake for their technical reviews of the manuscript. Lydia Corrill patiently edited an earlier version of the manuscript. Environmental Sciences Division Publication No. 3608. 


\section{MATHEMATICAL SYMBOLS}

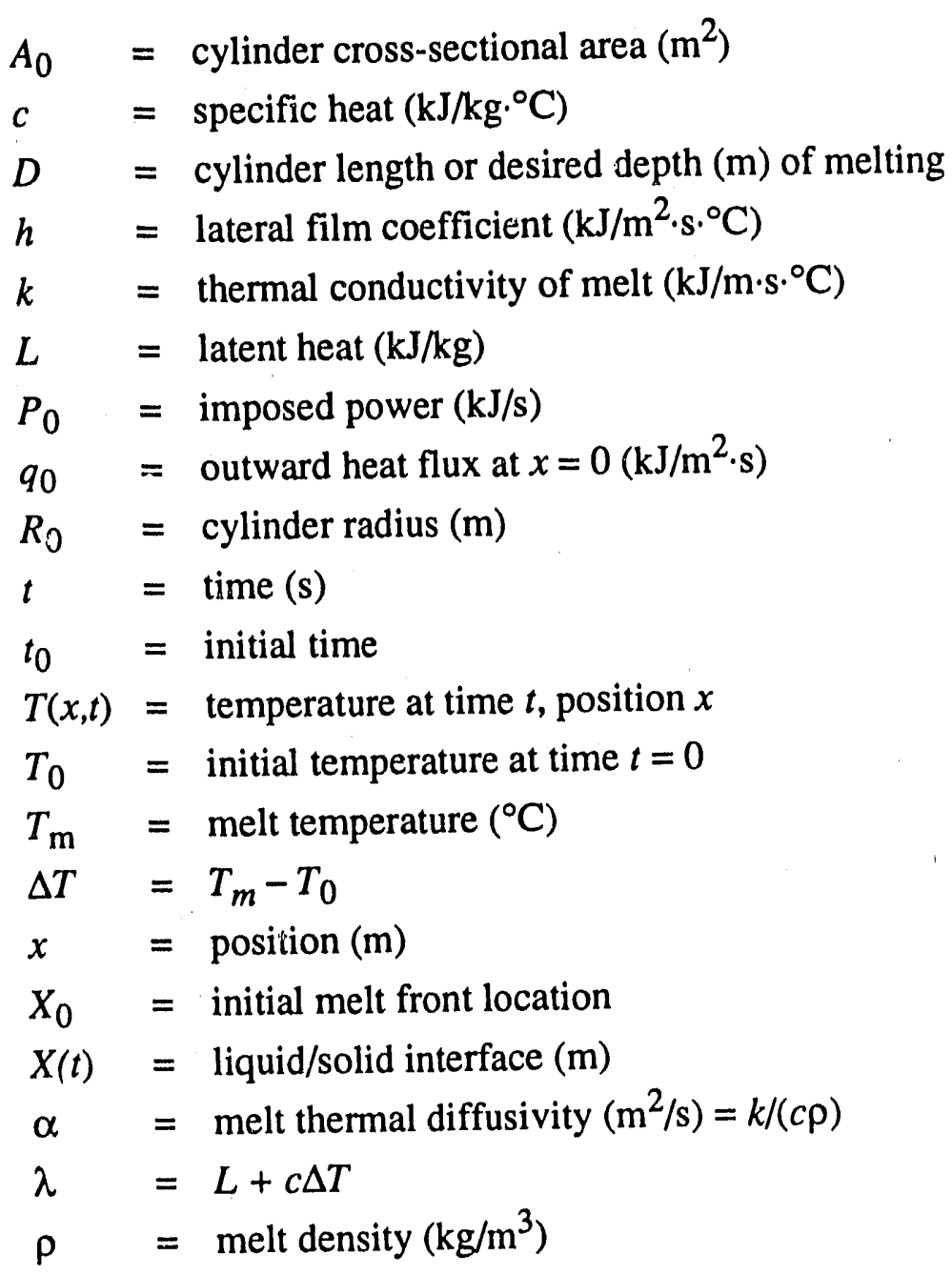




\section{EXECUTIVE SUMMARY}

In situ vitrification (ISV), developed by Pacific Northwest Laboratory and patented for the U.S. Department of Energy, is one method used to stabilize contaminated soils in place. ISV involves inserting four electrodes in a square array into contaminated soil and applying an electrical potential to the $\mathrm{e}^{\mathrm{y}}$ 'strodes. The soil is heated to above its melting point, and the molten zone expands with time to encompass the contaminated zone. After cooling, the resulting solid material is usually a mixture of glass and crystalline material that has a significantly higher resistance to leaching than did the original soils. Nonvolatile elements (most radionuclides and metals) are dissolved into the melt or encapsulated in glass if their solubility in the melt is low. Organic compounds tend to be pyrolyzed, with the decomposition products diffusing to the surface and combusting on exiting the molten zone. A hood is placed over the vitrification zone to collect off-gas particulates and volatiles into a processing trailer that scrubs contaminants from the off-gas.

Because ISV is used to immobilize highly hazardous wastes, a precise quantitative knowledge of the process is needed to determine where the melt zone is at a given time and whether hazardous materials are being released to the surrounding soil or the atmosphere during melting. ISV is based on the Joule heating concept and involves conduction, convection, diffusion, bubbling, and chemical reaction. Important design and operation issues involve the optimum configuration and placement of the electrodes and delivery of power to the melt. Previous models of ISV have been based on an assumed interface profile linked to heat and mass balances. They accurately predicted the ISV process in some cases, but not in others. These models are limited because they do not take into account all of the important and complex heat transfer processes occurring in the melt and the effect they may have on the temporal and spatial development of the melt front.

The current study identified key parameters and processes in the ISV melt cycle and developed an improved understanding of ISV. Analytical approximations for several properties of molten soil were determined from available data. Using a simplified geometrical approximation for melt geometry, an analytical approximation for the rate of melting (depth) vs time was derived that is consistent with data from field experiments. At small times, the depth of melting increases linearly with time. After approximately $10 \mathrm{~h}$ in large-scale tests, however, the depth increases as the square root of time. Existing data is also consistent with a relationship that shows the volumetric growth rate of the melt to be directly proportional to time. These conclusions suggest that heat transfer processes controlling the ISV process may be at the transition between weak convection and conduction.

Continued interpretation of additional test data and derivation of analytical models should lead to an improved understanding of controlling processes during ISV. In parallel, it is important to improve existing three-dimensional heat transfer models that can account for heat transfer, phase change, convection/conduction, electric field and power 
distributions, bubble formation and transport, chemical reaction, and vapor transport. Such a model would be useful for optimization studies of ISV designs, and providing added confidence in the application of ISV to contaminated sites. One important benefit of a dual approach (both analytical and numerical models) is the capability to approximate parameters that cannot be directly measured easily. 


\section{INTRODUCTION}

In situ vitrification (ISV) is one method used to stabilize contaminated soils in place. ISV was developed by Pacific Northwest Laboratory (PNL) and patented for the U.S. Department of Energy. The technology involves inserting four electrodes in a square array into the contaminated soil and applying an electrical potential to the electrodes. The soil is heated to above its melting point, and the molten zone expands with time to encompass the contaminated zone. After cooling, the resulting solid material is usually a mixture of glass and crystalline material that has a significantly higher resistance to leaching than did the original soils. Nonvolatile elements (most radionuclides and metals) are dissolved into the melt or encapsulated in glass if their solubility in the melt is low. Organic compounds tend to be pyrolyzed, with the decomposition products diffusing to the surface and combusting on exiting the molten zone. A hood is placed over the vitrification zone to collect off-gas particulates and volatiles into a processing trailer that scrubs contaminants from the off-gas. Additional details on the ISV technology can be found in Buelt et al. (1987).

ISV is being considered for application to contaminated sites at Oak Ridge National Laboratory (ORNL). In particular, seepage pits and trenches used to dispose of radioactive liquid wastes are under consideration for vitrification. Tests addressirg issues for the vitrification of pits and trenches at ORNL have been performed at the laboratory, engineering, and pilot scales (Carter et al. 1987, 1988; Spalding and Jacobs 1989). Previous results are encouraging, but several issues remain (Spalding and Jacobs 1989). First, a method to reduce the accumulation of ${ }^{137} \mathrm{Cs}$ in the off-gas trailer is required. Second, confirmation of the spatial configuration of the final melt zone is important to ensure that contaminated zones are completely encapsulated by the molten zone. Third, some of the pits and trenches are quite large and alternative electrode configurations may be more effective.

Because ISV is used to immobilize highly hazardous wistes, a precise quantitative knowledge of the process is needed to determine where the melt zone is at a given time and whether hazardous materials are being released to the surrounding soil or the atmosphere during melting. ISV is based on Joule heating and involves conduction, convection, diffusion, bubbling, and chemical reaction. Important design and operation issues include the optimum configuration and placement of the electrodes and delivery of power to the melt. To address these and similar questions, PNL developed a simplified computer model of ISV (Buelt et al. 1987). The model is based on an assumed interface profile linked to heat and mass balances; it accurately predicts the ISV process in some cases, but not in others. The PNL model is limited because it does not take into account all of the important and complex heat transfer processes occurring in the melt and the effect they may have on the temporal and spatial development of the melt front. The objectives of the current study include identifying the key parameters and processos in the ISV melt cycle and deriving improved models of ISV on the basis of available data and analytical techniques. 
The PNL model (Buelt et al. 1987) is based on an assumed shape of the melt front coupled to the heat balance properties of the buried material. The assumed shape of the melt zone can be described as approximately a box with its size determined by the electrode placement and the amount of heat generated. Heat lost to the surrounding environment (conducted to the adjacent ground or the upper surface) is small compared with the latent ${ }^{*}$ and sensible ${ }^{\dagger}$ heat content of the melt (see Sect. 5). 'The PNL model is a good tool for predicting small-scale ( $<1 \mathrm{~m}$ electrode spacing) ISV applications in homogeneous materials. For tests involving electrode spacings of $\sim 1 \mathrm{~m}$ and maximum power of $400 \mathrm{~kW}$, agreement between model results and observations for melt depth, melt width, mass vitrified, and run time to a given melt depth matches to within $10 \%$ relative error for burial sites consisting of essentially homogeneous soils. Heat balance models based on assumed shapes generally break down when the burial site is heterogeneous or the melt region becomes large enough to admit complex, nonuniform, convective behavior, partly a result of reduced temperature uniformity, greater extent of melt region, and greater nonuniformity of the electric field generating heat. Thus, for large-scale tests involving power up to $3000 \mathrm{~kW}$, run times of 60 to $160 \mathrm{~h}$, and electrode separations of $\sim 5 \mathrm{~m}$, the model predictions differed by as much as $40 \%$ from observed data for parameters such as meli depth. In a pilot-scale test at ORNL involving distinct regions of soil and crushed-limestone gravel, the required run time was twice that predicted, with a much larger melt mass required for the melt to reach the target depth (Spalding and Jacobs 1989). This discrepancy between the model and observations for the large-scale and nonuniform soil tests may be attributable to both large-scale flow phenomena and the different materials being melted at different positions and stages in the process.

In addition to neglecting key convective and electric field properties, the PNL model also ignores chemical effects, bubble behavior, and temperature variations in the melt. Thus, the model is limited in its capabilities to design control strategies and to determine desirable electrode placement. For example, to reduce the release of cesium to the ISV hood [an important consideration for sites at ORNL (Spalding and Jacobs 1989)], one possibility is to decrease the maximum temperature in the melt while maintaining a desired melt rate and a box-like shape of the melt region. One way to accomplish this goal would be to vary the power input, reducing the temperature as the melt passes through the contaminated zone. The PNL model cannot be used to explore such approaches because the melt shape is preassigned and local variability of temperature and heat generation is not included. In all the tests where the PNL model is inconsistent with the available data, the time predicted for the melt to reach a planned depth is too short, even though the energy balance is accurate to within $10 \%$. Hence, the PNL model is underestimating the heat transfer in the horizontal direction, the "lateral" heat transfer. This result was observed in the previous pilot-scale

*Latent heat $=$ energy $(\mathrm{kJ} / \mathrm{kg})$ required to melt the soil (i.e., heat of fusion).

$\dagger$ Sensible heat $=$ energy $(\mathrm{kJ} / \mathrm{kg})$ required to raise the temperature of the melt above its meltirig point $\left(T_{\mathrm{m}}\right)$. 
ORNL test. It is unclear whether the PNL model predicts just the melting process, or the entire ISV process including the cooling and crystallization cycles. When the power is shut off, much of the melt could be at temperatures well above its melting point, so there is a large reservoir of sensible heat still available for melting the surrounding soil as the molten zone cools; this reservoir is much larger than that associated with the latent heat of crystallization. This behavior may be evidenced in the difference between recorded melt depth [4.3 $\mathrm{m}$ at $160 \mathrm{~h}$ for the LSVT test (Buelt et al. 1987, Fig. 36, p. 67)] and the final depth of vitrification [5.0 m (Buelt et al. 1987, Table 26, p. 112)].

The rate of cooling determines the structure of the solid. Where slow cooling occurs, solidification takes a form typically associated with homogeneous nucleation of a constitutionally supercooled alloy system, with the formation of crystalline material of distinct compositions (Spalding and Jacobs 1989). In the phase transition from liquid to solid the material releases its latent heat. Whore cooling is rapid, a glass is formed that is an amorphous, viscous liquid that retains its latent heat (Goldstein and Simha 1976). Apparently, the PNL model does not incorporate the concept of latent heat and cannot predict cooling cycle behavior, spatial composition, or cooling rates.

The key parameter of phase change processes is the Stefan number,

$$
S t=\frac{c \Delta T}{L},
$$

where $c=$ specific heat, $\Delta T=$ temperature drop, $L=$ latent heat. For soil, typical values (Buelt et al. 1987) are $c=1.2 \mathrm{~kJ} / \mathrm{kg} \cdot{ }^{\circ} \mathrm{C}, L=400 \mathrm{~kJ} / \mathrm{kg}^{*}$ and $\Delta T=600^{\circ} \mathrm{C}$, hence $S t=1.8$. For processes with $S t$ in the range of 1 to 10 , both latent heat and sensible heat are important. Ignoring the latent heat results in overly optimistic system performance predictions (i.e., too short a time to melt to a desired depth).

* A value typical of earthen materials is assumed in this analysis (Robie et al. 1978). 


\section{DEVELOPMENT OF ALTERNATIVE CONCEPTUAL MODELS}

\subsection{HEAT TRANSFER MF.CHANISMS IN ISV}

The heat transfer and phase change processes in ISV are governed by one overriding fac!-the hottest point in the melt is neither at the bottom nor at the top. Recent PNL modeling studies have shown that the hottest regions of the melt probably occur in the upper one third of the melt with peak temperatures adjacent to the electrodes (Lowery, personal communication). Thus, while there may be convection from the core of the melt region to the top and the sides, there may be no or little convection from the bottom of the melt region to the central region because the bottom layer may be cooler, more dense, and more viscous because of its lower temperature resulting from heat losses as a result of contact with the cooler soil. A comparison to known conditions for natural convection in enclosed spaces (MicAdams 1954) suggests that the ISV process may be at the transition between weak convection and conduction. Convection from the center of the melt to the upper surface slows the conduction-driven downward melting because it increases heat loss toward the surface. Convection from the center of the melt to the lateral surfaces enhances heat transfer and melting in this direction, partially explaining the discrepancy between the PNL model and observations. A bottom, stagnant layer in which heat transfer is conduction-driven has been observed in the experimental work of Jaupart et al. (1984). It is probable that the "average" temperature of the melt region decreases with time from well above the melting temperature of the system to near the melting point as the surface area grows and heat losses to the ground and air increase. The process is sumplicated by the high temperature of the electrodes and the excellent heat transfer $a$ l. ung the griphite electrodes, both of which will influence the features or the stagnant layer and convection at the bottom of the melt. During the cooling cycle, heat transfer is primarily driven by conduction and will tend to "round out" the shape of the vitreous mass.

\subsection{HEAT BALANCE AND DEPTH BASED ON DATA}

The first step in analyzing the ISV data is to examine an energy inventory of the process. For the available data in Buelt et al. (1987), the latent heat contribution is $\sim 13 \%$ and sensible heat accounts for $\sim 62 \%$, while heat losses to the ground and air account for the remaining $-25 \%$. As noted previously, the discrepancy between the PNL model and observations appears to arise from an incomplete incorporation of the heat transfer modes into the model. From observations of melt depth as a function of time (Buelt et al. 1987, p.67), we observe that for up to $10 \mathrm{~h}$ on a large-scale, 150 - $\mathrm{h}$ test depth grows linearly in time at a rate of $0.13 \mathrm{~m} / \mathrm{h}$. Beyond $10 \mathrm{~h}$ the data points are well approximated by a squareroot-of-time dependence,

$$
D=W \sqrt{t} \text { for } W=\text { constant }=0.0054,
$$

with depth $D$ in $\mathrm{m}$ and time $t$ in $\mathrm{s}$. In general, constant front speed is indicative of a constant heat flux into the melt, whereas square-root-of-time dependence indicates an essentially 
constant driving temperature drop for conduction-driven heat transfer. Similar behavior is seen on the basis of burnout times for thermocouples in the pilot-scale ORNL test (Spalding and Jacobs 1987). For all reliable data points over a 60-h melt period (Spalding and Jacobs 1987, Fig. 20, p. 37), the ratio of depth to the square root of time is a constant (see Sect. 5).

\subsection{A MODEL CONSISTENT WITH DATA}

A simplified model that is consistent with the observed depth-time relation and the possibility of sirong lateral growth can be developed based on one-dimensional heat transfer along the axis of a cylinder with convective heat loss to the cylinder wall. A cylindrical geometry was chosen as a compromise between a realistic representation of the molten shapes found in field tests and the need for mathematical convenience. We assume a heat source term that is uniformly distributed in the (growing) melt region, with a strong heat loss through the upper cylinder face. The convective heat loss to the cylinder surface is governed by a heat transfer coefficient that can be estimated by natural convection-driven correlations for enclosed spaces (McAdams 1954). The model is described in detail in Sect. 4. Our key result thus far is the following relation for the depth of melting at large times:

$$
\text { Melt Depth }=\sqrt{\frac{k b P_{0} t}{\pi h R_{0} \rho \lambda}},
$$

wherein $k=$ melt thc $i$ mal conductivity $\left(\mathrm{kJ} / \mathrm{m} \cdot \mathrm{s} \cdot{ }^{\circ} \mathrm{C}\right), P_{0}=$ power $(\mathrm{kJ} / \mathrm{s}), t=$ time $(\mathrm{s})$, $\rho=$ density $\left(\mathrm{kg} / \mathrm{m}^{3}\right), \lambda=\mathrm{c} \Delta T+L, c=$ specific heat $\left(\mathrm{kJ} / \mathrm{kg} \cdot{ }^{\circ} \mathrm{C}\right), \Delta T=$ temperature drop $\left({ }^{\circ} \mathrm{C}\right)$, $L=$ latent heat $(\mathrm{kJ} / \mathrm{kg}), R_{0}=$ cylinder radius $(\mathrm{m}), h=$ film coefficient $\left(\mathrm{kJ} / \mathrm{m}^{2} \cdot \mathrm{s} \cdot{ }^{\circ} \mathrm{C}\right)$, and

$$
b=\sqrt{\frac{2 \pi R_{0} h}{A_{0} k}},
$$

for $A_{0}=$ cylinder cross-sectional area $\left(\mathrm{m}^{2}\right)$.

For small times (up to $\sim 10 \mathrm{~h}$ ), after a period of $\sim 2 \mathrm{~h}$ for the initial melt to be established at a temperature of $-2000^{\circ} \mathrm{C}$, the depth increases linearly. Thus, an explicit relation has been found for the depth for all times. Note that the film coefficient $h$ and the ambient temperature $T$ govern the heat transfer to the lateral surface and that $h$ depends exponentially on the temperature (Buelt et al. 1987).

Restating the preceding depth relation leads us to the identification of a key dimensionless variable

$$
\Omega=\left(\frac{P_{0}}{A_{0}}\right) /\left(\frac{k \Delta T}{D}\right),
$$


where $D$ is the overall cylinder length, or in our case, the desired depth. This relationship represents the ratio of heat generated per unit area of the cylinder cross section to the conduction-driven flux down the cylinder axis. The analytical approximations developed in this work (see Sect. 4) are straightforward enough to address questions related to differences in composition of the material at different depths and lateral distances.

If at a certain depth the material switches from being a loosely packed gravel to a tightly packed soil, then the key difference felt by the ISV process, outside of material effect on the electrical conductivity, thermal properties, etc., will be that resulting $f / w m$ the difference in density. Because the specific heat of most rocks and soils is roughly 1 to 2 $\mathrm{kJ} / \mathrm{kg} \cdot{ }^{\circ} \mathrm{C}$ and the conductivity of the solid effects only the width of the thermal boundary layer beyond the melt front, we believe that differences of $\sim 30 \%$ in thermal conductivity will not have a major effect on ISV. The major effect of nonuniformitv of the system will be felt via the density. Roughly speaking, for pure conductive heat transfer, the speed of propagation of the phase front is inversely proportional to the square root of time (Solomon 1979); when it is convection-driven, then the proportionality is direct (Rubenstein 1971). Evidence of this square-root-of-time behavior is seen in the results from the pilot-scale ORNL test. From this test (see Sect 5.2), there is also evidence that the rate of volume increase is linear with time. This behavior is consistent with "weak" convective heat transfer in the lateral direction and thus the square-root-of-time dependence of the rate of depth with time. 


\section{DEVELOPMENT NEEDS FOR ISV MODELS}

Our main goal until now has been to gain an understanding, consistent with observations, of the ISV mechanisms for heat transfer and phase change. In addition, we have studied the material properties, obtaining analytical approximations for a number of them for use in heat transfer models. Our work has taken geometrical options into account, including models of ISV for specific forms of the melt region and has resulted in a number of simple analytical models of ISV. Ultimately, a tool for prediction and optimization of the ISV process is needed that could be used to assist in design studies, in the planning for a new site, predicting the outcome of the process in a dependable and effective manner, and enabling the application of ISV with confidence.

A parallel modeling approach may be most beneficial. First, through continued assessment of test data and simplified analytical models, an understanding of what is happening in ISV can be incorporated into to a set of effective approximations for all factors important to melting and solidification behavior. Important processes and parameters include the (1) evolution of the melt front, (2) upper surface temperature, (3) "average" melt temperature, (4) distribution of electric field and temperature in the melt, (5) extent and form of the melt front during cooling, (6) role of bubble formation and transport within the melt on the mixing and release of volatiles, (7) transport of volatile materials within the surrounding soil, and (8) phase transformations and chemical reactions within the melt and along the contact with the soil. In particular, we can now meld our simple model to the lateral front shape via the temperature distribution and its local effect on the film coefficient, leading to a coupled system of ordinary differential equations that can be solved either numerically or analytically for various limiting cases (high $k, h$, etc.). Critical parameters already identified include the Nusselt and Stefan numbers, the aspect ratio of the melt, and the power generation flux to heat flux ratio $\Omega$ [defined in Eq. (5)]. It should also be possible to gain insight into the effect of a nonuniform electric field, resulting in a set of "rules of thumb" describing the necessary inputs (i.e., electrode spacing, and time) that will produce a given desired output (i.e., depth, maximum temperature, and melt configuration).

Second, a three-dimensional simulation code for the ISV process, incorporating heat transfer, phase change, natural convection, and the evolving electric field and power generation, should be developed. The code could assume either a sharp phase change or a phase change over a temperature range. For the latter it could predict the location of a "rnushy" zone of constitutionally supercooled material (Alexiades and Solomon 1989; Solomon et al. 1985; Alexiades et al. 1985), although assumptions would need to be made about the makeup and properties of the material. The approach should be one of adapting an existing multidimensional phase change/heat transfer code with convection and void formation (Wichner et al. 1988). A vital role in code validation and debugging will be played by the analytical models described in the previous paragraph. An expected benefit 
of both analytical and numerical models is their use in approximating parameters whose direct measurement is not possible, including the thermophysical properties of mixtures of materials typifying the melt during ISV.

The chief goal of ISV modeling efforts should be to enable optimization of the design and control of the ISV process (i.e., the large-scale system to be designed and built for use at ORNL). Questions that could be addressed include: For a given trench whose contents are incompletely known, where should electrodes (how many) be placed? What should be the (possibly time-dependent) power directed to these electrodes? Should the distribution of power be selective (i.e., how much is sent to which areas)? We can effectively address these questions by using the aforementioned combination of analytical models and the computer codes. In addition, modeling can be used to generate sensitivity or responsesurface models for ISV behavior. A final and immediate goal of the ISV modeling effort is to couple the ISV models with seismic models being developed to assist interpretation of the seismic studies for the tracer-level radioactive ORNL test planned for 1991. This synthesis would provide both the seismic and thermal modeling efforts with more information for validation and model calibration. 


\section{DERIVATION OF DEPTH VS TIME، RELATIONSHIPS}

In the case of the current study, we developed several analytical models for various concepts of ISV processes. These models include assumptions of actual melt front shapes and analytical relations derived from data. In this section we will briefly describe just two of these models. The first is a simple example in which we derive the square-root-of-time dependence of depth for a particular PNL experiment. The second is a partial derivation, without the analytical details, of the relation for depth introduced earlier (Eq. 3).

\subsection{SQUARE-ROOT-OF-TIME DEPENDENCE OF MELT DEPTH}

Table 1 summarizes depth vs time data from Buelt et al. (1987); the depth values are interpolated from Fig. 36 (p. 67).

Table 1. Depth vs time relationship for a large-scale ISV melt. ${ }^{\text {a }}$

\begin{tabular}{|ccc|}
\hline $\begin{array}{c}t \\
(\mathrm{~s})\end{array}$ & $\begin{array}{c}\text { depth } \\
(\mathrm{m})\end{array}$ & $W=\frac{\text { Depth }}{\sqrt{t}}$ \\
\hline 36000 & 1.00 & 0.0053 \\
144000 & 2.00 & 0.0053 \\
180000 & 2.33 & 0.0055 \\
360000 & 3.33 & 0.0056 \\
540000 & 4.00 & 0.0054 \\
\hline
\end{tabular}

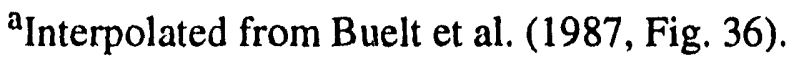

Because square-root-of-time dependence is generally indicative of conductive phase change processes, it is interesting to see that $W$ is nearly constant. From the quasi-stationary approximation to the one-dimensional, single-phase Stefan problem (Solomon 1979), a reasonable approximation to $W$ is

$$
W=2 \sqrt{\frac{k \Delta T}{2 \rho L}},
$$

where $p, k, L$, and $\Delta T$ are the density, conductivity, latent heat, and temperature drop, respectively. The overall system temperature drop ${ }^{*}$ in a typical ISV test is approximately $\Delta T=1000^{\circ} \mathrm{C}$, while the density of the melt is $\rho=2200 \mathrm{~kg} / \mathrm{m}^{3}$ (Buelt et al. 1987). As a

*Defined as the drop in temperature from the melt to the temperature of the heated, but not melted, surrounding soil $\left(1400-400^{\circ} \mathrm{C}\right)$. 
representative value for the latent heat of earthen materials, we take $L=400 \mathrm{~kJ} / \mathrm{kg}$ (Robie et al. 1978). Substitution of these values into this expression and setting $W=0.0054$ yields the conductivity value $k=0.0128 \mathrm{~kJ} / \mathrm{m} \cdot \mathrm{s} \cdot{ }^{\circ} \mathrm{C}$. The conductivity data of Buelt et al. $(1987, \mathrm{p}$. 91 ) indicate that this value corresponds to the actual value of the conductivity at $1400^{\circ} \mathrm{C}$, which is the conductivity of the melt at the upper limit of its melt temperature range. Thus, the assumption of depth growth being strongly conduction driven is reasonable.

\subsection{MODEL OF MELT PROGRESSION AS A FUNCTION OF TIME}

The solution to the classical Stefan problem of melting of a semi-infinite slab as a result of an imposed constant face temperature for an initially uniform temperature has a phase change interface whose progress is proportional to the square root of time,

$$
X=W \sqrt{t} \text {, where } W \text { is a constant. }
$$

All available data for the melt depth as a function of time shows the same kind of behavior for large times, while for small times depth is directly proportional to time. Hence, at first glance one is tempted to conclude that, as in the Stefan problem case, conduction is the prime process for heat transfer to the bottom of the ISV melt. For ISV, however, in place of a constant imposed face temperature we have a distributed power source in the melt. For the one-dimensional case, it can be shown that the resulting front will be proportional to time $t$ itself. How do we explain a phase change front proportional to the square root of time for large times and directly to time for small times? The solution we have formulated serves at least two purposes: (1) it yields the desired qualitative front behavior and (2) it helps us to identify certain critical dimensionless parameters characterizing ISV behavior. Our problem is defined in an idealized one-dimensional form; a long cylinder from which heat is extracted convectively at its lateral surface and on the end caps. For homogeneous systems, a cylinder is a reasonable approximation and is mathematically convenient to illustrate key concepts.

Consider a region of cross-sectional area $A_{0}$ and length $D$ (desired total depth of melting). The region may be taken as a cylinder of radius $R_{0}$. Let the $x$-axis be placed along the axis of the cylinder, with $x=0$ corresponding to the top face. Assume that it is initially solid at temperature $T_{0}<T_{\mathrm{m}}$. We further assume that through some mechanism a melting process is initiated at the top face of the cylinder and that an internal heat source of power $P_{0}$ is distributed uniformly through the melt region at all time. From some positive time onward, heat is lost out the top with a known flux $q_{0}$, while heat is lost to the lateral cylinder surface via convective cooling to the walls, maintained at the melt temperature, with a film coefficient $h$. Under these conditions a melt region growing down the cylinder with time is generated. We wish to find approximations to the melt front and temperature distribution in terms of the time for large time. 
Based on properties for typical soils and rocks, it is reaconable to assume that the solid material ahead of the interface $X(t)$ has a low conductivity, and hence a sharp gradient exists from the interface into the solid. We also assume that heat transfer is effectively carried out by conduction down the length of the cylinder. In this simplistic approximation, convective effects simply amount to an enhanced conductivity. Where convection dominates, its effect will be that of an enhanced conductivity. Note that the temperature is assumed to be essentially uniform in cross section [i.e., it can be represented as $T(x, t)$ with no lateral dependence]. Under these assumptions we wish to estimate the temperature $T(x, t)$ and the phase change front $X(t)$ satisfying the following conditions:

$$
\begin{aligned}
c \rho \frac{\partial T}{\partial t}=k \frac{\partial^{2} T}{\partial x^{2}}(x, t)-\left(\frac{2 \pi R_{0} h}{A_{0}}\right)\left(T-T_{\mathrm{m}}\right)+\frac{P_{0}}{A_{0} X}, \quad(0<x<X(t)), \\
T(X(t), t)=T_{\mathrm{m}}, \\
-k \frac{\partial T}{\partial x}(0, t)=-q_{0}, \\
\rho(L+c \Delta T) \frac{\partial X}{\partial t}(t)=-k \frac{\partial T}{\partial x}(X(t), t), \\
X\left(t_{0}\right)=X_{0} .
\end{aligned}
$$

Note that in our formulation we have embedded the sensible heat stored in the soil $c \Delta T$ in the latent heat for the phase front energy conservation condition [Eq. (11)].

The effective Stefan number of our phase change is $c \Delta T /(L+c \Delta T)<1$. Convection will tend to drive the temperature to its steady-state value for any position $X(t)$ attained by the phase change front. Hence, we anticipate that the quasi-stationary arproximation to the solution, obtained by replacing Eq. (8) by its steady-state counterpart, can effectively approximate the true solution to the problem. Hence, we replace Eq. (8) by the equation

$$
0=k\left(\frac{\partial^{2} T}{\partial x^{2}}(x, t)\right)-\left(\frac{2 \pi R_{0} h}{A_{0}}\right)\left(T-T_{\mathrm{m}}\right)+\frac{P_{0}}{A_{0} X} \quad, \quad 0<\mathrm{x}<\mathrm{X}(\mathrm{t}) .
$$

The problem consisting of (Eqs. 8a, 9, 10, and 12) can be solved explicitly in the form

$$
T=T_{\mathrm{m}}+\left(\frac{P_{0} R_{0}}{2 h A_{0} X(t)}\right)+A e^{b(x-X(t))}+B e^{-b(x-X(t))},
$$

with 


$$
b=\sqrt{\frac{2 \pi R_{0} h}{A_{0} k}},
$$

wherein the constants $A, B$ are determined from the conditions

$$
\begin{gathered}
A+B=-\frac{P_{0} R_{0}}{2 h A_{0} X(t)}, \\
A e^{-b X(t)}-B e^{b X(t)}=\frac{q_{0}}{k b} .
\end{gathered}
$$

In addition, from Eq. (13)

$$
\frac{\partial T}{\partial x}(x, t)=A b e^{b(x-X(t))}-B b e^{-b(x-X(t))} .
$$

Upon solving for $A$ and $B$ from Eqs. $(15,16)$ and substituting Eq. (17) into the interface condition [Eq. (11)] we obtain a differential equation for $X(t)$ which can then be solved numerically. If, however, we merely wish to determine the behavior of $X(t)$ for large $t$ (e.g., to determine the time dependence for large $t$ ), we need only note that for large $X(t)$ Eqs. (15, 16) show that approximately

$$
A \approx-\left(\frac{P_{0} R_{0}}{2 h A_{0} X(t)}\right), \quad B \approx 0 .
$$

Thus at the interface $x=X(t)$,

$$
\frac{\partial T}{\partial x}(X(t), t)=A b=-\frac{b P_{0} R_{0}}{2 h A_{0} X(t)} .
$$

Upon substitution into the front condition Eq. (11) and solving the resulting ordinary differential equation we obtain

$$
X(t)=\sqrt{X_{0}^{2}+\frac{k P_{0} R_{0} b\left(t-t_{0}\right)}{h A_{0} \rho \lambda}} .
$$

This result establishes the square-root-of-time dependence of the front for large time. We note that $X(t)$ depends on essentially every factor in our problem, most notably the film coefficient to the lateral surface $h$, the power generation rate $P_{0}$, and the conductivity $k$. In turn, the film coefficient $h$ is determined by the natural convection arising from the internal heat generation and the fact that temperature attains a maximum for some positive $x$, decreasing both for increasing and decreasing $x$. The film coefficient is strongly dependent on the viscosity of the liquid which, in turn, is highly dependent on temperature. It is 
interesting to represent the relation Eq. (20) in terms of dimensionless groups. If we introduce the dimensionless time $\tau$,

$$
\tau=\frac{\alpha t}{D^{2}}=\text { Fourier Number, where } \alpha=\frac{k}{\rho c},
$$

and the dimensionless interface location,

$$
\sigma(\tau)=\frac{X(t)}{D}
$$

then Eq. (20) takes the form

$$
\sigma(\tau)=\sqrt{\sigma_{0}^{2}+\gamma^{2}\left(\tau-\tau_{0}\right)},
$$

with

$$
\gamma^{2}=\Omega \cdot S t \cdot\left(\frac{R_{0}}{D}\right) \cdot \sqrt{\frac{2}{v}},
$$

where

$v=$ Nusselt number

$$
v=\frac{h R_{0}}{k},
$$

$\Omega=$ ratio of power flux to the temperature flux

$$
\Omega=\left(\frac{P_{0}}{A_{0}}\right) /\left(\frac{k \Delta T}{D}\right),
$$

$S t=$ Stefan number

$$
S t=\frac{c \Delta T}{\lambda}
$$

and

$$
\frac{D}{R_{0}}=\text { Aspect Ratio of Melt }
$$

Note that $\Omega$ is just the ratio of the Rayleigh number associated with convection resulting from an internal heat source to convection in an enclosed region resulting from a temperature drop (McAdams 1954). 
We note that our process must begin at some time $t_{0}$ with a finite melt region; otherwise, there is no heat generation while heat is lost at the surface. From Eqs. $(15,16)$ we can see that for small times $t$ the growth of the front is linear in time. We conclude that our model qualitatively fits the observations on depth history. A more precise model can be built upon Eq. (20) when we incorporate temperature dependence of the conductivity and viscosity. 


\section{OBSERVATIONS}

This section summarizes observations of ISV processes and parameters from the PNL experiments (Buelt et al. 1987) and the ORNL experiment (Spalding and Jacobs 1989) and serves as part of the basis for the results presented in this report.

\subsection{NOTES ON THE PNL EXPERIMENTS}

Form of solid obtained: Solidified material appears both as a glass and in crystalline form. We note that when an amorphous glass is formed, the latent heat of melting of the original material is not liberated.

Composition of solid: ISV appears to distribute all materials evenly throughout the melt. This behavior can be attributed to factors that include "convective currents" and bubbling, particularly from the phase-change front.

Shape of the front: The statement that the vitrified product is "almost square in shape" (Buelt et al. 1987, p. ix) is not necessarily always true, as can be seen in the experiments described later in Buelt et al. (1987) and in the pilot-scale ORINL test (Spalding and Jacobs 1989). The shape of the front depends on the interaction of mechanisms for heat transfer within the melt and is not solely determined by the electric field.

Global heat balance: Much of the heat generated by ISV is released in the off.gas stream. In ISV there are two obvious sources of heat: (1) the electric field in the melt and (2) any exothermic chemical reactions that might be taking place. It appears doubtful that the latter could be significant. The heat generated either heats up the melt, heats up the surrounding thermal layer of soil, melts the soil, or leaves the melt region via convection to the "atmosphere" beneath the hood or in gas bubbles leaving the melt. We have not yet developed a complete heat balance for the experiments.

Position of radionuclides: Radionuclides can be expected to be located near the bottom of pits and trenches at ORNL (Spalding and Jacobs 1989). As the melt front reaches the contaminated zone, bubbling at the front will result in radionuclide particles being brought to the upper levels of the melt. Indeed, this is considered the likely "escape route" for cesium in previous ORNL tests. If the region of strong convection does not reach these greater depths (i.e., if a stagnant layer exists), the deeper portions of the vitrified solid could contain a higher concentration of radionuclides. However, results from the pilot-scale ORNL test (Spalding and Jacobs 1989) did not indicate this behavior. Thus, other processes may act to promote mixing of this lower region with the strongly convecting region of melt, for example, the bubbling front or the contact of the melt with the electrodes. The electrode feeding technique planned for future ISV applications will influence these processes. 
In the central portions of the melt where couling is slow, the radionuclides are more likely to be found in crystalline solid than in glass after the ISV process is completed (depends on bulk composition, rate of cooling, and crystal-liquid partition factors). For the pilot-scale ORNL test, the compositions of crystalline spherulites and glass were identical on a gross scale $(>-50 \mu \mathrm{m})$. At a scale of $<10 \mu \mathrm{m}$, individual crystalline phases (pseudowollastonite and a feldspar-like phase) have unique compositions.

Cold cap: The air temperature beneath the hood is significantly lower than the melt temperature when a negative pressure is applied beneath the ISV hood. In this case, a cold cap is formed above the melt. During uctive melting this cap is a layer of solid/ liquid froth. If the cap is "solid" and the melt wets the electrodes (as is the case for molybdenum electrodes) so that gases cannot escape at those points of contact, then the cold cap may prevent gases from leaving the melt, and the cap may be observed to rise (i.e., actually "climb" up the electrodes). A rising cap creates potential problems of gas release as well as treatment of the area after the ISV process is completed. The cap can be melted only by a heat source in the vicinity of the ground level; the electrodes. By placing large-diameter graphite collars around the molybdenum, PNL was able to (1) enhance the heat transfer capability of the electrodes and (2) promote nonwetting of the melt to the electrodes. Tests have demonstrated the success of this approach. Currently, uncoated graphite electrodes are used in an automatic electrode-feeding mechanism, which alleviates tnis problem.

Description of the early stages of ISV: "The ... power heats the starter path and surrounding soil initially to $2000^{\circ} \mathrm{C}$, well above soil-melting temperatures of 1100 to $1400^{\circ} \mathrm{C}$. The graphite starter path is eventually consumed by oxidation, and the current is transferred to the molten soil, operating between 1450 and $1600^{\circ} \mathrm{C}$," (Buelt et al. 1987 , p. 2).

Composition of soil vs electric field: The composition of the material is of crucial importance to electrical conductivity and heat generation in ISV. Thus, soil with too great a concentration of sodium is not amenable to ISV because it is too conductive (Buelt et al. 1987, p.4).

Conductivity of graphite: Conductivity of graphite is about 100 times that of soil (McAdams 1954).

Combustibles: It is stated (Buelt et al. 1987, p. 24) that buried solid and liquid combustibles have raised the off-gas temperature to a maximum value of $750^{\circ} \mathrm{C}$.

Power curve in time: The power over the ISV run attains a relatively constant value after a brief start-up period. 
Rate of growth of vertical melt front: In Buelt et al. (1987, p. 67), we see the melt front depth as a function of time. Up to $10 \mathrm{~h}$, the four depth measurements lie precisely on a straight line whose slope is $0.13 \mathrm{~m} / \mathrm{h}$ and which is given by

$$
Y=0.13(t-2.27), \quad \text { where } t=\text { time }(\mathrm{h}) \text { and } Y=\operatorname{depth}(\mathrm{m}) \text {. }
$$

From 10 to $150 \mathrm{~h}$, the data points [depth (m), time (s)] are fit well by

$$
Y=W \sqrt{t}, \quad \text { for } W=0.0054 \text {. }
$$

Constant front speed is indicative of a constant heat flux into a melting body, while squareroot-of-time dependence indicates melting driven by an essentially constant temperature drop.

Role of modeling: Buelt et al. (1987, p. 67) state that "power input and system design parameters combined with mathematical modeling are not a direct method of measurement ..." Indeed, a modeling activity must be focused in two directions: optimal setup of the ISV application and real-time interactive optimal use of ISV. The former must operate on known elements of the process, such as early linear growth of melt depth, whereas the latter must attempt to determine parameters for this linear growth using off-gas and thermocouple data.

Performance constraint: The electrode must not be exposed to temperatures greater than $1750^{\circ} \mathrm{C}$ (Buelt et al. 1987, p. 73).

Leachability of crystalline solid: Buelt et al. (1987, p. 79) state that ISV glass containing a crystalline phase exhibits a slightly improved leach resistance. In terms of leaching from the solid, it might be of value to cycle a sample of the crystalline solid in water-saturated soil through repeated temperature swings (e.g., $90^{\circ} \mathrm{F}$ to $-30^{\circ} \mathrm{F}$ ) to test for any fracturing of the solid and the resulting impact on leachability.

Thermal conductivity of molten soil: The thermal conductivity of molten soil is graphed in Buelt et al. (1987, p. 91, Fig. 43). The portion of the figure for temperature $T>1000^{\circ} \mathrm{C}$ can be fit by the straight line

$$
k(T)=k_{1}+k_{2}(T-1400)
$$

for $k$ in $\mathrm{kJ} / \mathrm{m} \cdot \mathrm{s} \cdot{ }^{\circ} \mathrm{C}, T$ in ${ }^{\circ} \mathrm{C}$, where

$$
k_{1}=13.6 \times 10^{-3}, k_{2}=29 \times 10^{-6}
$$


Electrical conductivity as a function of temperature: The electrical conductivity of typical molten soils can be approximated as

$$
e\left(\mathrm{ohm}^{-1} \cdot \mathrm{cm}^{-1}\right)=45.7 \times 10^{-5300 /(T+273)},
$$

where $T$ is in ${ }^{\circ} \mathrm{C}$.

Viscosity of molten soils: The viscosity of molten Hanford soils (Buelt et al. 1987, p. 100) can be well approximated by the relation

$$
\mu(\mathrm{kg} / \mathrm{in} \cdot \mathrm{s})=\left(6.9 \times 10^{-5}\right) \times 10^{11100 /(\mathrm{T}+273)},
$$

where $T$ is in ${ }^{\circ} \mathrm{C}$.

Specific heat of molten soil: The specific heat of the molten soil is a relatively constant value (Buelt et al. 1987, p. 95) of

$$
c=0.28 \mathrm{cal} / \mathrm{g} \cdot{ }^{\circ} \mathrm{C}=1.17 \mathrm{~kJ} / \mathrm{kg} \cdot{ }^{\circ} \mathrm{C} .
$$

Current as a function of time for a large-scale test: The measured current between electrodes for a large-scale ISV test (Buelt et al. 1987, p. 41) can be represented analytically as

$$
t)= \begin{cases}4.5 \times 10^{-2} t & \text { for } t<3.7 \times 10^{4} \\ 1666+6.16 \times 10^{-3}\left(t-3.7 \times 10^{4}\right) & \text { for } 3.7 \times 10^{4}<t<3.07 \times 1( \\ 3333 & \text { for } t<3.07 \times 10^{5}\end{cases}
$$

Density of molten soils: A representative density of molten soil is $\rho=2300 \mathrm{~kg} / \mathrm{m}^{3}$.

Coefficient of expansion: The coefficient of expansion of molten soil is found from the density versus temperature curve of Buelt et al. $(1987$, p. 101) as

$$
\beta=-(1 / \rho)\{\partial \rho / \partial T\}=10^{-4} /{ }^{\circ} \mathrm{C}
$$

Heat fluxes in the PNL test: A representative surface temperature is taken to be $570^{\circ} \mathrm{C}$, which implies a solid crust at the upper surface. Based on this value, the surface flux from the upper surface is a high value of $32 \mathrm{~kJ} / \mathrm{m}^{2} \cdot \mathrm{s}$; that into the ground is reported as $3.2 \mathrm{~kJ} / \mathrm{m}^{2} \cdot \mathrm{s}$. 
Heat balance for PSFT-1 ISV test: The conditions and actual data are

$$
\begin{aligned}
& \text { Electrode spacing }=1.15(\mathrm{~m}) \\
& \text { Surface heat flux }=32\left(\mathrm{~kW} / \mathrm{m}^{2}\right) \\
& \text { Soil heat flux }=3.2\left(\mathrm{~kW} / \mathrm{m}^{2}\right) \\
& \text { Average }\left(\text { melt) temperature }=1900\left({ }^{\circ} \mathrm{C}\right)\right. \\
& \text { Run time }=21(\mathrm{~h}) \\
& \text { Run time }=75.6 \times 10^{3}(\mathrm{~s}) \\
& \text { Melt depth }=1.1(\mathrm{~m}) \\
& \text { Mass vitrified }=5670(\mathrm{~kg}) \\
& \text { Total energy }=4300(\mathrm{kWh}) \\
& \text { Total energy }=15.5 \times 10^{6}(\mathrm{~kJ})
\end{aligned}
$$

We take the specific heat and latent heat values as

$$
\begin{aligned}
& c=1.17\left(\mathrm{~kJ} / \mathrm{kg} \cdot{ }^{\circ} \mathrm{C}\right) \\
& L=400(\mathrm{~kJ} / \mathrm{kg})
\end{aligned}
$$

Then, the total latent heat used in the ISV test is

$$
L_{\mathrm{tot}}=2.27 \times 10^{6} \mathrm{~kJ}
$$

Assuming that over the ISV process the "average" temperature of the melt is $1600^{\circ} \mathrm{C}$, the sensible heat contribution is

$$
S H_{\mathrm{tot}}=10.6 \times 10^{6} \mathrm{~kJ}
$$

The total heat lost in the ISV process is

$$
\text { Total energy }-L_{\mathrm{tot}}-S H_{\mathrm{tot}}=2.63 \times 10^{6} \mathrm{~kJ}
$$

The heat loss through the top, assuming a constant heat flux out the top of $32 \mathrm{~kJ} / \mathrm{m}^{2} \cdot \mathrm{s}$ is found to be

$$
\text { Loss through top }=3.2 \times 10^{6} \mathrm{~kJ}
$$

Assuming an average depth of $0.6 \mathrm{~m}$ and a heat flux of $3.2 \mathrm{~kJ} / \mathrm{m}^{2} \cdot \mathrm{s}$, the heat loss through the sides and bottom of a "box-like" shape would be 


$$
\text { Loss to ground }=1 \times 10^{6} \mathrm{~kJ}
$$

The discrepancy in a global heat balance is approximately $10 \%$, which, in vic:" of the uncertainties surrounding many of the quantities (such as "average temperature" and shape), is reasonable.

Similar results are obtained for the PSRT ISV test, except that a heat balance demands a lower effective average melt temperature.

Density difference between soil and rock: Soil and rock densities can be taken as representative values of 1600 and $2200 \mathrm{~kg} / \mathrm{m}^{3}$, respectively. Thus, the actual mass of material vitrified is

$$
\operatorname{Mass}(\mathrm{kg})=V \times 1600
$$

where $V=$ the volume vitrified. If the vitrified region is assigned a box-like shape with depth $d$ and side length $a$, then this mass is

$$
\text { Mass }(\mathrm{kg})=d \times a^{2} \times 160()
$$

This relationship seems to be the basis for the volume and mass figures given in Tables 24 and 25 of Buelt et al. (1987, p. 108).

Data in Tables 24, 25, and 26: For $P, V$ the total power used and volume of soil vitrified, respectively, if we assume a square box shape we find that

$$
P / V=3.6 \times 10^{6}
$$

Similarly, if $d_{\text {elec }}$ is the electrode spacing and $d_{\text {vit }}$ is the side length of the vitrified region, we find

$$
d_{\mathrm{vil}} / d_{\mathrm{elec}}=1.5
$$

For a vitrified depth $d$,

$$
V=d \times d_{\mathrm{vit}}^{2}=2.25 \times d \times d_{\mathrm{elec}}^{2}
$$

while,

$$
V=(P / 3.6) \times 10^{-6},
$$


from which we conclude that

$$
d=\left(2.25 \times d_{\mathrm{elec}}^{2}\right)^{-1} \times(P / 3.6) \times 10^{-6}=0.12 \times 10^{-6} \times P / d_{\mathrm{elec}}^{2}
$$

The four ISV tests discussed in Buelt et al. (1987) were analyzed in this fashion and the results are presented in Table 2.

Note that for tests I-IV our crude estimate is accurate to within abouł $10 \%$ relative error. This agreement is good because it corresponds to a heat balance that excludes shape and the more delicate relationships between growth in the horizontal and vertical directions. Indeed, the relation between $P$ and $V$ may be estimated by excluding all losses as

$$
P=(c \Delta T+L) \times \rho \times V
$$

The last test, whose run time is more than twice that of the others, is in error in the same manner as that of the PNL computer model, namely overestimating depth and underestimating breadth of the melt. Indeed, as the melting process proceeds, the rate of heat transfer in the horizontal direction will grow compared with the declining rate of descent of the melt front, because the former is driven by natural convection, which in turn is driven by the internal heat source.

Table 2. Relationships among power, depth of melting, and electrode spacing. ${ }^{\mathrm{a}}$

\begin{tabular}{|llccccc|}
\hline Test & $\begin{array}{l}d_{\text {elec }} \\
(\mathrm{m})\end{array}$ & $\begin{array}{c}P \\
(\mathrm{~kJ})\end{array}$ & $\begin{array}{c}d_{\text {vit }}(\text { true }) \\
(\mathrm{m})\end{array}$ & $\begin{array}{c}d_{\text {vit }}(\mathrm{est}) \\
(\mathrm{m})\end{array}$ & $\begin{array}{c}d \text { (true }) \\
(\mathrm{m})\end{array}$ & $\begin{array}{c}d(\mathrm{est}) \\
(\mathrm{m})\end{array}$ \\
\hline I & 1.15 & $1.6 \times 10^{7}$ & 1.8 & 1.7 & 1.1 & 1.4 \\
II & 1.2 & $2.5 \times 10^{7}$ & 1.8 & 1.8 & 1.5 & 2.1 \\
III & 5.0 & $7.6 \times 10^{8}$ & 7.0 & 7.5 & 4.0 & 3.65 \\
IV & 5.0 & $5.6 \times 10^{8}$ & 7.5 & 7.5 & 3.0 & 2.7 \\
V & 5.0 & $1.7 \times 10^{9}$ & 10.6 & 7.5 & 5.0 & 8.2 \\
& & & & & & \\
\hline
\end{tabular}

${ }^{a}$ Calculated from data in Buelt et al. (1987).

Final state: It is interesting to examine the final cooled state of the ISV system. We note that even when power is shut off a large pool of residual sensible heat remains which is substantially larger than the latent heat that will still be available for melting. This residual heat is manifested in the difference of the recorded melt depth of about $4.3 \mathrm{~m}$ at $160 \mathrm{~h}$ for 
the LSVT test of Buelt et al. (1987, Fig. 36, p. 67) and the actual vitrified depth for this run of $5.0 \mathrm{~m}$ (Buelt et al. 1987, Table 26, p. 112). Upon examining the data of Tables 25 and 26 (Buelt et al. 1987) for depth $d(\mathrm{~m})$ and duration of heating $t(\mathrm{~h})$, we find that the ratio

$$
d / t^{0.63}
$$

results in the fairiy constant values $0.16,0.21,0.30,0.20,0.20$, and 0.20 for the six tests recorded. The last two correspond to the LSOAT-3 and LSVT tests. We believe that such a relation will result from a combination of a global latent heat balance and an estimate of the relative heat transfer rates in the vertical and horizontal directions. Note in particular that the value 0.20 applies also to the LSVT test, in which other depth predictions are in great error.

\subsection{NOTES ON THE ORNL EXPERIMENT}

Vitrified mass in the ORNL ISV test: $2 \times 10^{5} \mathrm{~kg}$

Time of power application: $110 \mathrm{~h}=3.96 \times 10^{5} \mathrm{~s}$

Total power used: $104.4 \times 10^{6} \mathrm{~kJ}$

Amount of heat going into melting: Based on a latent heat of $400 \mathrm{~kJ} / \mathrm{kg}$, the mass vitrified requires $80 \times 10^{6} \mathrm{~kJ}$, implying a loss of about $24.4 \times 10^{6} \mathrm{~kJ}$.

\section{Rate of power generation: $260 \mathrm{~kJ} / \mathrm{s}$}

Solid product formed: The solid appearing after completion of the ISV run consisted of a mixture of crystalline rock (spherulites), in which at least two materials of different composition are present, and an amorphous glass which retains its latent heat.

Composition of the melt: A large portion of the ISV material in the ORNL test was crushed limestone with the density of $1440 \mathrm{~kg} / \mathrm{m}^{3}$.

Width of the melt: The width of the melt region as appearing in Spalding and Jacobs (1989, p. 20, Fig. 9), appears to be about 1.5 times the electrode width. On the other hand, along the trench length where the material is primarily crushed limestone, the extent of melting is approximately three times the electrode width.

Hood surface temperature: The hood surface temperature was approximately unchanging at $-100^{\circ} \mathrm{C}$ during the entire ISV run. 
Progress of vertical melt front: Table 3 summarizes the depth vs time relationship for the pilot-scale test based on the burnout times for thermocouples found in Spalding and Jacobs (1989, Fig. 20, p. 37). We see that the depth is again essentially proportional to the square root of time, which typically represents front propagation via predominantly pure conduction.

Table 3. Depth vs time relationshipa.

\begin{tabular}{|ccc|}
\hline $\begin{array}{c}\text { Time } \\
(\mathrm{s})\end{array}$ & $\begin{array}{c}\text { Depth } \\
(\mathrm{m})\end{array}$ & Depth/Time $^{0.5}$ \\
\hline 20. & 0.9 & 0.20 \\
25. & 1.2 & 0.24 \\
50. & 1.5 & 0.21 \\
& & \\
\hline
\end{tabular}

aInterpolated from Spalding and Jacobs (1989, Fig. 20, p. 37)

Importance of chemical analysis: There is a need to correlate the convection and bubbling of the melt with the dispersion of trace amounts of cesium, strontium, etc. Thus, it is not clear that lowering melt temperature and viscosity will reduce cesium volatilization because its boiling point is far below the ISV melt temperature; however, the dispersion and absorption of gaseous cesium will be affected by these factors. In addition, the actual mechanism of volatilization is unknown; thus, other parameters may be important.

Linear volumetric growth rate of melt: One implication of the rate of increase of aluminum and silicon in the off-gas scrub solution is the approximately linear growth of the volume of melt in time. Together with Eq. (3), this result provides additional evidence for "weak" convective heat transfer in the lateral melt direction. This result is seen as follows.

Let $d(t)$ and $r(t)$ denote the depth and side length, respectively, of a box-shaped (assumed) melt at time $t$. From Eq. (3),

$$
d(t) \propto t^{1 / 2},
$$

while on the basis of the aluminum and silicon data, for the melt volume $V(t)$,

$$
\frac{\partial V}{\partial t} \propto t .
$$

But 


$$
V(t)=d(t) r(t)^{2}
$$

implying that

$$
\frac{\partial V}{\partial t}=\frac{\partial d}{\partial t} r(t)^{2}+2 r(t) \frac{\partial r}{\partial t} d(t) \propto t
$$

From Eq. (29),

$$
d(t) \propto t^{1 / 2}
$$

and

$$
\frac{\partial d}{\partial t} \propto t^{-1 / 2}
$$

Thus,

$$
r(t)^{2} t^{-1 / 2}+2 r(t) \frac{\partial r}{\partial t} t^{1 / 2} \propto t
$$

If we seek $r(t)$ in the form $r(t) \propto t^{\mathrm{m}}$, we find that $\mathrm{m}=3 / 4$, or $r(t) \propto \mathrm{t}^{3 / 4}$. Since lateral growth of the melt is governed by

$$
\rho L \frac{\partial r}{\partial t}=h \Delta T
$$

we conclude that

$$
h \propto \frac{\partial r}{\partial t} \propto t^{-1 / 4} \propto r^{-1 / 3}
$$

Thus, the Nusselt number,

$$
v=\frac{h r}{k} \propto r^{2 / 3}
$$

For natural convection (McAdams 1954, p. 181),

$$
v \propto r^{3 n}
$$

where $n=0$ corresponds to pure conduction and $n \geq 1 / 4$ corresponds to natural convection effectively controlling heat transfer. The case where $v \propto r^{2 / 3}$ implies that $n=2 / 9<1 / 4$, which corresponds to the case where neither convection nor conduction dominates the other and both need to be taken into account. 
Electrode spacing: The spacing between electrodes is $1.25 \mathrm{~m}$. Because subsidence of the vitrified mass is $\sim 0.91 \mathrm{~m}$, the reduction in volume of the melt is $1.42 \mathrm{~m}^{3}$.

Use of cooling models for core data: It has been seen in the PNL data that the residual sensible heat in the material at the end of the power cycle is large enough to promote further melting and growth of the melt region. From the time when the power cycle is over, the temperature in the melt declines and the melt expands. The cooling rate at each point in the melt helps determine whether the material at that point will be amorphous glass or a crystalline material (for some materials, the presence of nucleation sites is critical also). It should be possible to meld the core sample data with analytical approximations to cooling rates to gain more precise information about the final state of the material and the extent of melting. It is our belief that convection plays a small role during the cooling cycle and that further growth of the melt region is almost entirely conduction-driven. It would be interesting to examine the backward phase change problem, beginning with the final solidified shape and asking what was the shape at the end of the power cycle by using the additional information accorded by the core samples. 


\section{REFERENCES}

Alexiades, V. and A. Solomon (1989) The formation of a solid nucleus in supercooled liquid, II, Journal of Non-Equilibrium Thermodynamics 14, 99-109.

Alexiades, V., D. Wilson and A. Solomon (1985) Macroscopic global modeling of binary alloy solidification processes, Quarterly of Applied Mathematics 43, 143-158.

Buelt J., C. Timmerman, K. Oma, V. FitzPatrick, and J. Carter (1987) In situ vitrification of transuranic waste: An updated systems evaluation and applications assessment, PNL-4800, Suppl. 1, Pacific Northwest Laboratory, Richland, Washington.

Carter, J., S. Bates, and D. Maupin(1987) In Situ Vitrification of Oak Ridge National Laboratory soil and limestone, PNL-6174, Pacific Northwest Laboratory, Richland, Washington.

Carter, J., S. Koegler, and S. Bates (1988) Process performance of the pilot-scale in situ vitrification of a simulated waste disposal site at the Oak Ridge National Laboratory, PNL-6530, Pacific Northwest Laboratory, Richland, Washington.

Goldstein, M. and R. Simha, eds. (1976) The glass transition and the nature of the glassy stage, Annals of the New York Academy of Sciences 279.

Jaupart, C., G. Brandeis and C. Allegre (1984) Stagnant layers at the bottom of convecting magma chambers, Nature 308, 535-538.

McAdams, W. (1954) Heat Transmission, McGraw-Hill, New York.

Ostrach, S. (1988) Natural convection in enclosures, Journal of Heat Transfer 110, 1175 1190.

Robie, R. A., B. S. Hemingway, and J. R. Fischer (1978) Thermodynamic Properties of Minerals and Related Substances at $298.15 \mathrm{~K}$ and 1 bar ( $10^{5}$ Pascals) Pressure and at Higher Temperatures, U.S. Geological Survey Bulletin 1452, Washington, D.C.

Rubenstein, L. I. (1971) The Stefan Problem, Translations of Mathematical Monographs 27, American Mathematical Society, Providence, RI. (translated from Russian)

Solomon, A. (1979) Mathematical modeling of phase change processes for latent heat thermal energy storage, ORNL/ CSD-39, Oak Ridge National Laboratory, Oak Ridge, Tennessee.

Solomon, A., V. Alexiades and D. Wilson (1985) A numerical simulation of a binary alloy solidification process, SIAM Journal of Scientific Computing 6, 911-922. 
Spalding, B. and G. Jacobs (1989) Evaluation of an In Situ Vitrification Field Demonstration of a Simulated Radioactive Liquid Waste Disposal Trench, ORNL/TM10992, Oak Ridge National Laboratory, Oak Ridge, Tennessee.

Wichner, R., J. Drake, A. Solomon, P. Williams and G. Giles (1988) Thermal analysis of heat storage canisters for a space power, solar dynamic system," Proceedings of the International Solar Energy Conference, American Society of Mechanical Engineers. 
ORNL/ER-30

\section{DISTRIBUTION}

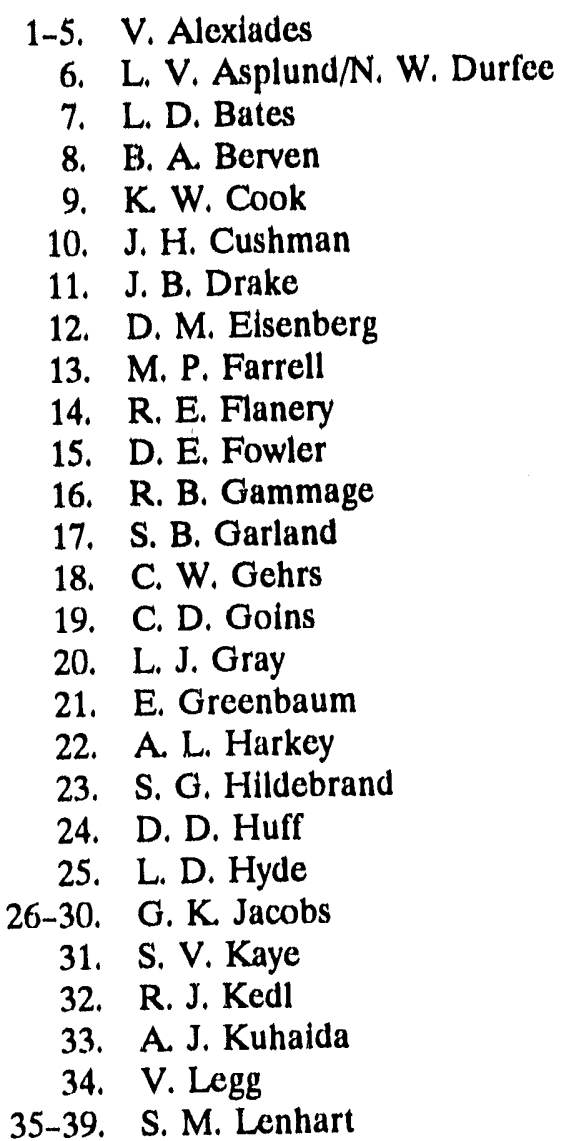

40. A. P. Malinauskas

41. J. C. Moyers

42. M. T. Naney

43-47. J. E. Nyquist

48. M. Olszewski

49-50. P. T. Owen

51. D. E. Reichle

52. G. E. Rymer

53. P. A. Schrandt

54. D. S. Shriner

55. B. P. Spalding

56. S. H. Stow

57. D. W. Swindle

58. J. L. Tomlinson

59. R. I. Van Hook

60. L. D. Voorhees

61. R. C. Ward

62. D. R. Watkins

63. R. K. White

64-68. ER Document Management Center

69. Central Research Library

70-74. ESD Library

75. ORNL Y-12 Technical Library

76. Laboratory Records Dept.

77. Laboratory Records, ORNL-RC

78. ORNL Patent Section

79. Office of Assistant Manager for Energy Research and Development, DOE Oak Ridge Field Office, P.O. Box 2001, Oak Ridge, TN 37831-8600

80. D. Adams, Mathematics Department, University of Kentucky, Lexington, KY 40506

81. J. Beult, Pacific Northwest Laboratory, P.O. Box 999, Richland, WA 99352

82. W. Bonner, Pacific Northwest Laboratory, P.O. Box 999, Richland, WA 99352

83. J. Conway, Mathematics Department, University of Tennessee, Knoxville, TN 37996

84. R. Deal, Chemistry Department, Kalamazoo College, Kalamazoo, MI 49001

85. J. G. Droppo, Battelle Northwest, P.O. Box 999, Richland, WA 99352

86. P. H. Edmonds, Radian Corporation, 120 South Jefferson Circle, Oak Ridge, TN 37830

87. J. F. Franklin, Bloedel Professor of Ecosystem Analysis, College of Forest Resources, University of Washington, Anderson Hall (AR-1C), Seattle, WA 98195

88. H. Hoffman, PAI Corporation, 116 Milan Way, Oak Ridge, TN 37830

89. G. M. Hornberger, Professor, Department of Environmental Sciences, University of Virginia, Charlottesville, VA 22903

90. G. Y. Jordy, Director, Office of Program Analysis, Office of Energy Research, ER-30, G-226, U.S. Department of Energy, Washington, DC 20545

91. J. R. Kannard, Program Manager, Bechtel National, Inc., P.O. Box 350, Oak Ridge Corporate Center, 151 Lafayette Drive, Oak Ridge, TN 37830 
92. P. Lowery, Pacific Northwest Laboratory, P.O. Box 999, Richland, WA 99352

93. W. C. Luth, Geosciences Research Program, Office of Basic Energy Research, U.S. Department of Energy, Washington, DC 20585

94. J. O. Moore, DOE Oak Ridge Field Office, P.O. Box 2001, Oak Ridge, TN 37831-8541

95-98. W. E. Murphie, Department of Energy, Office of Environmental Restoration, Eastern Area D\&D Branch, EM-423 (GTN), Washington, DC 20545

99. R. H. Olsen, Vice President for Research, University of Michigan, 6643 Medical Science Building II, Ann Arbor, MI 48109-0620

100. M. Oxley, Department of Mathematics and Statistics, School of Engineering, Air Force Institute of Technology, Wright-Patterson AFB, OH 45433

101. A. Patrinos, Acting Director, Environmental Sciences Division, Office of Health and Environmental Research, ER-74, U.S. Department of Energy, Washington, DC 20585

102-103. S. S. Perkins, DOE Oak Ridge Field Office, Information Resource Center, 105 Broadway, Oak Ridge, TN 37830

104. M. E. Peterson, Pacific Northwest Laboratory, P.O. Box 999, Richland, WA 99352

105-106. S. P. Riddle, DOE Oal: Ridge Field Office, P.O. Box 2001, Oak Ridge, TN 37831-8541

107. R. C. Sleeman, DOE Oak Ridge Field Office, P.O. Box 2001, Oak Ridge, TN 37831-8541

108-112. A. D. Solomon, P.O. Box 227, OMER 84965, ISRAEL

113. J. Stottlemyre, Pacific Northwest Laboratory, P.O. Box 999, Richland, WA 99352

114. F. J. Wobber, Environmental Sciences Division, Office of Health and Environmental Research, Office of Energy Research, ER-74, U.S. Department of Energy, Washington, DC 20584

115-116. Office of Scientific and Technical Information, P.O. Box 62, Oak Ridge, TN 37831 

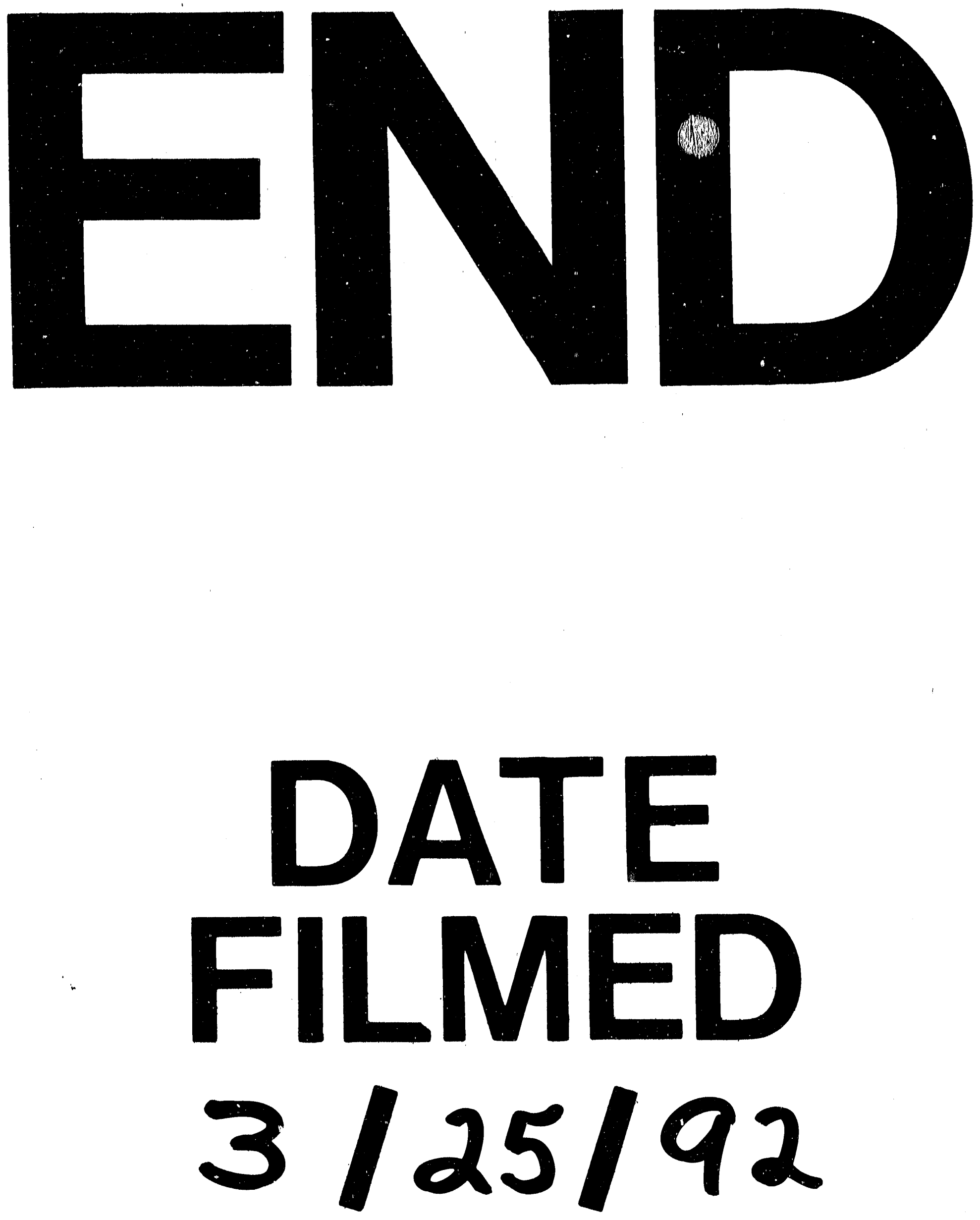
